\title{
Relation of Abnormal Cytological Smears and Carcinoma of Cervix Uteri to Husband's Occupation
}

\author{
JOHN WAKEFIELD, R. YULE, ALWYN SMITH, A. M. ADELSTEIN
}

British Medical foumal, 1973, 2, 142-143

\begin{abstract}
Summary
An analysis of the cytological records of almoet 300,000 women in the Manchester area shows that the rates of positive/suspicious findings from population screening are highly correlated with the rates of mortality from cancer of the cervix when both are distributed according to the occupation of the husband. The correlation holds for various occupational groupings and for all the individual occupation units in which there are more than 1,000 women. This evidence strengthens the case for believing that the condition revealed by a positive smear is a stage in the development of invasive cancer of the uterine cervix.
\end{abstract}

\section{Introduction}

In spite of many reports of the effects of mass cervical cytological screening (Boyes et al., 1970; Christopherson et al., 1970; MacGregor et al., 1971) and of many investigations of the aetiology (Boyd and Doll, 1964; Elliott, 1964) and epidemiology of carcinoma of the cervix uteri (Hill and Adelstein, 1967), doubts still remain as to the nature of the connexion, if any, between the condition of carcinoma in situ, which accounts for most positive cytological smears, and invasive cancer. Knox (1966) summarized the inadequacies in the present evidence. We now report evidence from a study of a large number of cytological records that the rates of positive smears are highly correlated with rates of mortality from cancer of the cervix when both are distributed according to the husband's occupation.

\section{Material and Method}

The linked records of women screened in the Manchester area have been recorded on computer tape since October 1965 for the primary purpose of organizing regular recall. The cytological record card is very similar to that introduced as a national record card early in 1972 and includes information on the husband's occupation, or the woman's own occupation if she is not married. This information is coded according to the 212 occupational units in the Registrar General's (1966) Classification of Occupations, each of which covers a group of related occupations. The occupational units are, in turn, commonly grouped into 26 larger occupational "orders" containing

\footnotetext{
University Hospital of South Manchester, Christie Hospital and Holt Radium Institute, Manchester M20 9BX

JOHN WAKEFIELD, B.A., PH.D., Director, Department of Social Research R. YULE, F.R.C.S., M.R.C.O.G., Consultant Pathologist, Diagnostic Cytology

University of Manchester, Clinical Sciences Building, York Place, Manchester M13 0J

ALWYN SMITH, PH.D., F.R.C.P., Professor of Social and Preventive Medicine

Office of Population Censuses and Surveys, Somerset House, Strand, London WC2R 1LR

A. M. ADELSTEIN, M.D., D.PH., Chief Medical Statistician
}

related units for example, order IX groups together all people employed in leather industries.

This report deals with the records of 292,155 women examined in the Manchester area's population screening programme between October 1965 and January 1972. They came from general practitioners (39\%), local health authority clinics (33\%), Family Planning Association clinics (22\%), and hospitals $(6 \%)$. The records have been analysed by occupational units and the prevalence of suspicious or positive findings per 1,000 calculated for each. "Positive or suspicious findings" in this context apply to cytological findings based on the initial smear; they do not refer to the subsequent history after histological examination.

The standardized mortality ratios (S.M.R.) used in the Results section were extracted from the Registrar General's (1971) Occupational Mortality Tables. They refer to cancer of the cervix uteri for married women in England and Wales in the years 1959-63.

\section{Results}

The data are given in the table in occupational orders from 1 to 26 in order of prevalence of positive smears, with the lowest rate at the top (professional, etc. workers, occupational order XXV) and the highest (labourers not elsewhere classified, occupational order XVIII) at the foot of the table. The number of women in each order is, with two minor exceptions (863 and $811)$, well over 1,000 .

Positive Findings in Rank Order with Standardized Mortality Ratios (S.M.R.) for Cancer of Uterine Cervix. (Roman Numerals are those used by the Office of Population Censuses and Surveys to Identify the Occupational Orders)

\begin{tabular}{|c|c|c|c|}
\hline Occupational Orders & $\begin{array}{c}\text { No. } \\
\text { of } \\
\text { Women }\end{array}$ & $\begin{array}{c}\text { No. } \\
\text { Positive } \\
\text { per } 1,000\end{array}$ & S.M.R.* \\
\hline 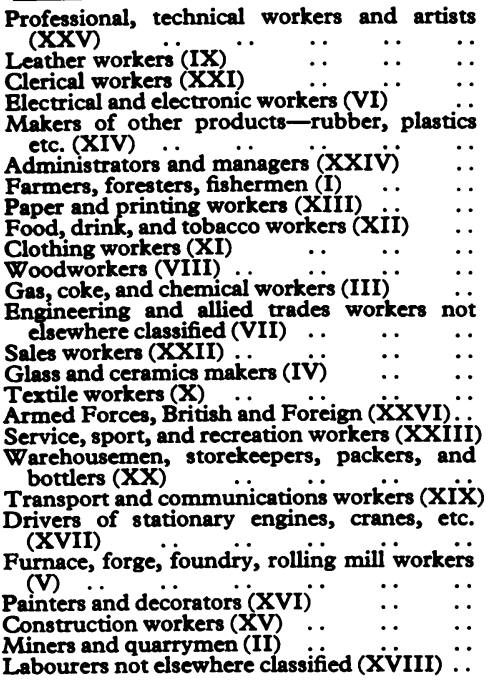 & $\begin{array}{r}37,700 \\
811 \\
28,013 \\
11,588 \\
2,770 \\
14,659 \\
4,645 \\
4,067 \\
3,571 \\
2,178 \\
6,466 \\
4,861 \\
47,108 \\
21,796 \\
863 \\
3,121 \\
1,588 \\
14,542 \\
5,018 \\
26,631 \\
3,045\end{array}$ & $\begin{array}{r}4.11 \\
4.93 \\
6.00 \\
7.08 \\
7.58 \\
8 \cdot 12 \\
8.40 \\
8.61 \\
8.96 \\
9.18 \\
9 \cdot 28 \\
9.87 \\
10.02 \\
10.41 \\
11.59 \\
11.86 \\
11.96 \\
12.17\end{array}$ & $\begin{array}{c}42 \\
103 \dagger \\
67 \\
92 \\
\\
88 \\
50 \\
93 \\
66 \dagger \\
117 \\
79 \dagger \\
77 \\
123 \\
96 \\
71 \\
84 \dagger \\
146 \\
102 \\
112 \\
81 \\
145 \\
150\end{array}$ \\
\hline
\end{tabular}

* Standardized mortality ratios from the Office of Population Censuses and Surveys. tBased on fewer than 50 actual deaths. Spearman rank correlation coefficient: $r s=0.672 ; t=4.446 ;$ D.F. $=24$. 
When the S.M.R. values for each occupational order are also placed in rank order the Spearman rank correlation coefficient indicates a high degree of correspondence $(r=$ $0.672 ; P<0.001$ ) between the two rankings.

The data have been analysed in a number of ways and with various occupational groupings. For example, if the 61 individual occupation units in which there are more than 1,000 women are extracted and placed in rank order there is a similarly high degree of correlation $\left(r_{s}=0.555 ; P<0.001\right)$ between the rank order series for positive findings and S.M.R. values.

The data are given in a different way in the chart. For each occupational order the prevalence of a positive smear is plotted against its S.M.R. In this chart we have removed fishermen and seamen from their usual orders (I and XIX) and have combined them into a new order having a prevalence of 23.85 per 1,000 and a S.M.R. of 262. The line is drawn through those occupational orders which are in the same position in the rank orders for both crude positive rate and S.M.R. The proximity of the points to this line is remarkable, and only the point numbered 28 (occupations inadequately described for accurate classification) lies any distance from the line.

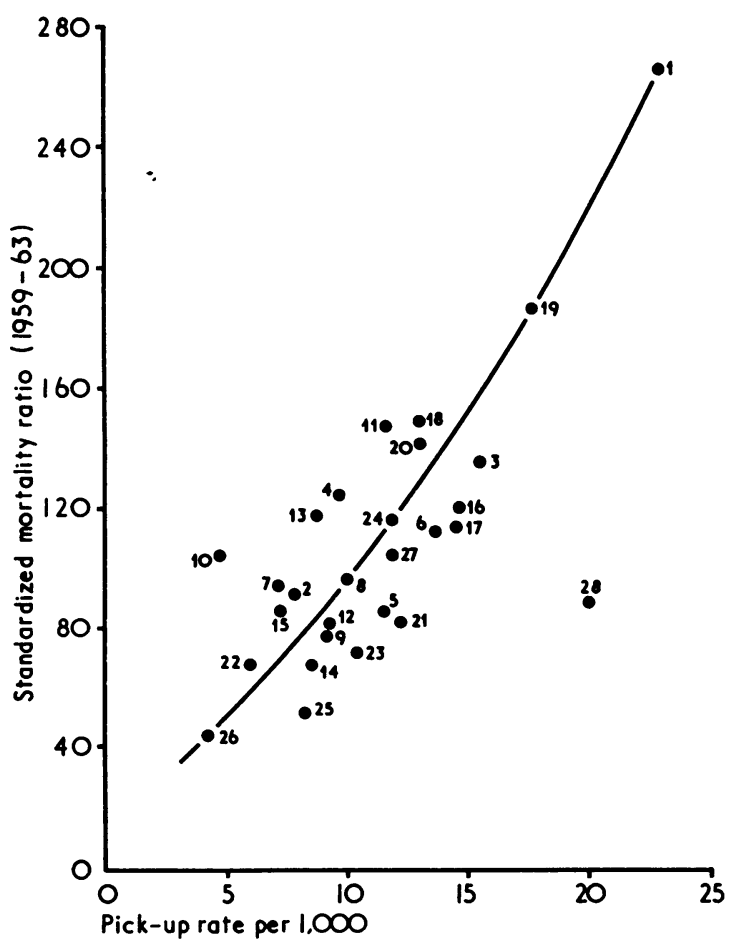

Prevalence of positive smears plotted against standardized mortality ratio for each occupational order.

Key to Occupational Orders:

1. Fishermen and seamen. 2. Farmers, foresters. 3. Miners and quarrymen. 4. Gas, coke, and chemicals makers. 5. Glass and ceramics makers. 6. Furnace, forge, foundry, rolling mill workers. 7. Electrical and electronic workers 8. Engineering and allied trades workers not elsewhere classified. 9. Wood workers. 10. Leather workers. 11. Textile workers. 12. Clothing workers 13. Food, drink, and tobacco workers. 14. Paper and printing workers 15. Makers of other products. 16. Construction workers. 17. Painters and 15. Makers of other products. 16. Construction workers. 17. Painters and decorators. 18. Drivers of stationary engines, cranes etc. 19. Labourers not elsewhere classified. 20. Transport and communications workers. 21. Warehousemen, storekeepers, packers, bottlers. 22. Clerical workers. 23. Sales workers. 24. Service, sport, and recreation workers. 25. Administrators and managers. 26. Professional, technical workers, artists. 27. Armed forces (British and foreign). 28. Inadequately described occupations.

\section{Discussion}

From the results presented here it is clear that the distribution by occupation of suspicious/positive findings from cytological population screening is remarkably similar to that of deaths from cancer of the uterine cervix among married women in the years before screening began. (Mortality rates by occupation are not available for any more recent period.) This finding, taken in conjunction with earlier evidence that a positive smear is associated with marital status (Sansom et al., 1971) in a manner comparable with that of mortality from cervical cancer, suggests strongly that the development of the abnormal cells found in positive smears is determined by factors similar to those which determine the development of carcinoma of the cervix.

Two possibilities will have to be entertained. First, that carcinoma in situ and invasive carcinoma are similarlv caused but not related to each other; and second, that carcinoma of the cervix may develop from carcinoma in situ. The first is unlikely and, if the latter is accepted, the close similarity between the two conditions suggests that known enidemiolneical features of carcinoma of cervix are more likely to initiate the carcinoma in situ-carcinoma process than to determine its progression.

The association of cancer of the cervix with husband's ococupation bas been known for some time. It has, however, more usually been considered in terms of the Registrar General's broader classification of occupations into social classes, because class has seemed a more plausible aetiological factor than occupation itself.

The findings described here highlight the specificity of these rates (bnth clinical and preclinical) in groupings narrower than social classes. We feel that this strengthens the case for believing that the histological changes noted in screening are related to the cancer and that the most likely explanation is that the cytological changes, and in particular carcinoma in situ, are precursors of clinical cancer.

Though it does not answer all the unresolved questions regarding the natural historv of carcinoma in situ so lucidly posed by Knox (1966), the close correspondence found between the prevalence of carcinoma in situ and mortality rates for invasive cancer goes some way towards answering the proper doubts he expressed. It does not, however, throw light on the crucial problem-whether the removal of precancerous lesions will necessarilv alter the natural history of carcinoma of the cervix and improve survival.

We plan to repeat our analysis when we have collected larger numbers of records. If the association between the prevalence of suspicious and positive cytological smears and mortality rates for a large range of occupational groupings is confirmed we must conclude that it constitutes strong evidence that the condition shown by an abnormal cytological smear is a stage in the development of invasive carcinoma of the cervix uteri.

We wish to thank Mrs. Jean Hill and Mrs. Ruth Glentworth who were responsible for the occupational coding, and Mrs. A. Fish for help with the statistical treatment.

This research was financed by grants from the Department of Health and Social Security and the Manchester Regional Hospital Board.

\section{References}

Boyd, J. T., and Doll, R. (1964). British fournal of Cancer, 18, 419

Boyes, D. A., Worth, A. J., and Fidler, H. K. (1970). Fournal of Obstetrics and Gynaecology of the British Commonwealth, 77,769.

Christopherson, W. M., Mendez, W. M., Ahuja, E. M., Lundin, F. E., and Parker, J. E. (1970). Cancer, 26, 29.

Elliott, R. I. K. (1964). Lancet, 1, 231.

Hill, G. B., and Adelstein, A. M. (1967). Lancet, 2, 605.

Knox, E. G. (1966). In Problems and Progress in Medical Care, ed. G. McLachian. London, Oxford University Press.

Macgregor, J. E., Frazer, M. E., and Mann, E. M. F. (1971). Lancet, 1, 74 Registrar General (1971). Decennial Supplement, 1961: Occupational Mortaity Tables. London, H.M.S.O.

Registrar General (1966). Classification of Occupations, 1966. London, H.M.S.O.

Sansom, C. D., Wakefield, J., and Yule, R. (1971). Medical Officer, 126, 253. 